\section{HELP DEFEAT MDS AND BLOOD CANCER}

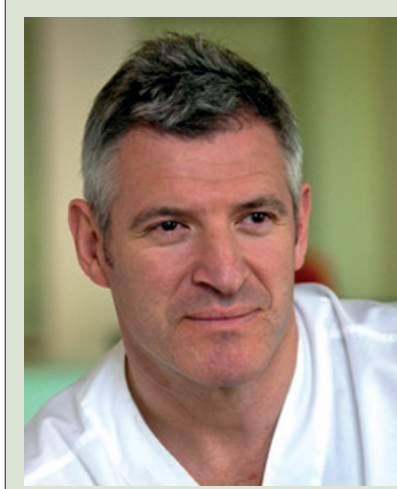

Leading dental technician Luke Barnett is calling on those in the dental field to support his campaign to help defeat MDS (myelodysplastic syndrome) and blood cancer.

Luke's 20-year-old niece Alice has MDS, a blood disorder which can lead to acute myelogenous leukemia, and she is writing a frank, funny and heartfelt blog about facing the condition and all that it entails. Her inspiring blog can be found at www.alicebyron.com

Luke said, 'I am devastated for my niece and no-one at the age of 20 with their entire life in front of them should have to face this kind of condition. That is why I am asking all those who can to take just a couple of minutes and sign up to become a donor so that we can beat MDS and all blood cancers.

'All that you need to do is to run a swab around your cheek and then send back in the envelope provided - and that's it! Surely we can all take two minutes out of our busy lives to do this? The more people who are on the registers, means more chance of finding a match. The odds are that you will never be called upon, but if you are then you alone will have the opportunity to give someone else a second chance of life by donating some of your blood stem cells.'

For those lucky enough to be under 30, please visit www.anthonynolan. org/apply-join-bone-marrow-register and if you are aged 30-55 please visit www.deletebloodcancer.org.uk/en/register-now.

\section{NEW PATIENT ADVICE RESOURCE LAUNCHED}

In conjunction with the Rheumatology department at King's College London, an online patient advice article has been published to advise patients with rheumatoid arthritis (RA) on how to main-
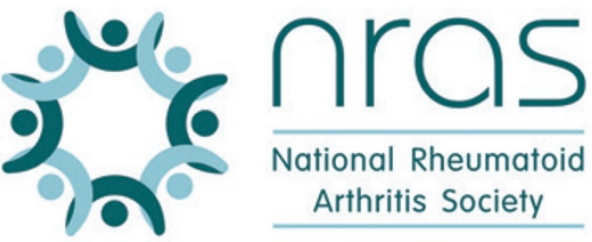

National Rheumatoid Arthritis Society
There has always been a long-standing, observational link between periodontal disease and RA, with Hippocrates suggesting centuries ago that pulling teeth could cure arthritis. Fortunately, with the medical and dental treatments available these days, this is not necessary or recommended!

Patients with RA can experience problems with their mouths. Some are directly related to RA such as periodontal disease, jaw problems and xerostomia, and some are indirectly related to RA; being a result of RA medication or caused by difficulty with cleaning the mouth (due to problems with other joints). This will not be a problem for all people with RA, but it may be helpful to be aware of these potential problems. The online resource provides information for dentists and DCPs on how to care for and offer advice to patients presenting with RA.

The oral health section of this online resource has been put together by Rupinder K. Bansal (dentist), Miranda Steeples (dental hygienist-yherapist) and Savia de Souza (Honorary Patient Expert, Academic Rheumatology, King's College London). Visit http://www.nras.org.uk/oral-health to view the resource.

\section{DATE FOR THE DIARY}

Following the success of the inaugural one day conference in 2015, the BDA South West

Young Dentist Group presents a sec-

ond one day conference on Saturday 20 February at Sandy Parks, starting at $9 \mathrm{am}$. Some of the best speakers and clinicians in the country will come together, for one day only, to give like-minded, enthusiastic young dentists the South West's biggest dental conference.

The highly esteemed Zaki Kanaan will be giving his expert opinion on all things whitening. Specialist periodontist Hatem Algraffee will be discussing periodontal litigation and what we should be doing. BDA Chair of the Executive Committee will be giving a talk on the future of dentistry for young dentists and Simon Tucker will also be giving his advice on communication and sales. Mark Singh, a fantastic speaker, will provide vital tips in all things medical.

This is certainly a day not to miss with international calibre speakers.

There are a range of sponsors who will be there to provide delegates with information and advice on their services, as well as contributing to the event.

A day pass for foundation dentists is £45. Early bird prices are at £95 until 20 January and £125 thereafter for non-foundation dentists.

Dental hygienists/therapists and nurses are welcome at $£ 45$ and $£ 25$ respectively.

For further information visit www.eventbrite. co.uk/e/bda-south-west-ydg-one-day-conferencetickets-19644897417?utm_term=eventurl_text

\section{CALLING ALL DENTAL PROFESSIONALS - HAVE YOUR SAY}

The third NHS Confidence Monitor survey is now live for all dental professionals to share their views. Its aim is to provide a better understanding of the profession's confidence levels in NHS dentistry.

The preceding NHS Confidence Monitor, conducted in May and June of 2015, solicited over 300 responses from dentists across the UK. To reflect the profession's

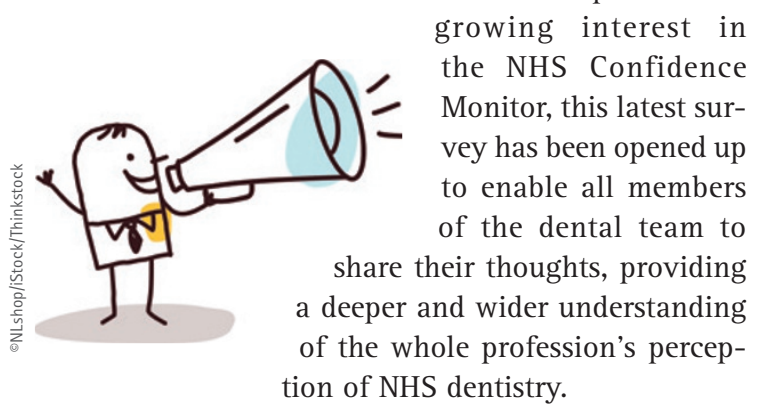

To take part in the latest NHS Confidence Monitor and share your thoughts, please visit https://www.surveymonkey.com/r/PracticePlanNHSConfidencemonitor3 before the closing date of 31 January, 2016. 